\title{
¿EN QUÉ CONTRIBUYE EL FEMINISMO PRODUCIDO \\ EN LAS REDES SOCIALES A LA AGENDA FEMINISTA?
}

\author{
HOW FEMINISM PRODUCED IN SOCIAL NETWORKS \\ CONTRIBUTES TO THE FEMINIST AGENDA?
}

Silvia Gas Barrachina
Universitat Jaume I

\section{RESUMEN}

Las redes sociales son interpretadas como espacios horizontales y de colectividad que favorecen los usos comunicativos y los modos de interacción de los movimientos sociales. El feminismo contemporáneo es partícipe de los beneficios que ofrecen los medios sociales digitales ya que suponen un medio para su difusión y creación de alianzas, del mismo modo que un nexo de convergencia de las pluralidades y puesta en común. Pero, a su vez, es atravesado por condicionantes inherentes a las redes sociales y propios del discurso neoliberal. Teniendo en cuenta que las redes sociales responden a nuevas vías útiles para el movimiento feminista por su capacidad de organización, difusión de la información y generar conocimientos, este trabajo cuestiona la relación entre dicho movimiento y las redes sociales con el fin de vislumbrar las características del feminismo que se sucede en estas plataformas y los efectos producidos en la agenda feminista.

Palabras Clave: feminismo, neoliberalismo, redes sociales, Facebook, Instagram, Youtube.

\section{ABSTRACT}

Social networks are interpreted as horizontal and collective spaces assisting communicative uses and the modes of interaction of social movements. Contemporary feminism benefits from digital social media because we can share information and create alliances. But, at the same time, it is crossed by inherent social networks' conditions associated with neoliberal discourse. Social networks respond to new useful ways for the feminist movement by its capacity for organization, dissemination of information and generate knowledge. This article will identify the relationship between feminism and social networks in order to highlight the characteristics of feminism in these plafforms and the effects produced in the feminist agenda.

Keywords: feminism, neoliberalism, social networks, Facebook, Instagram, Youtube. 


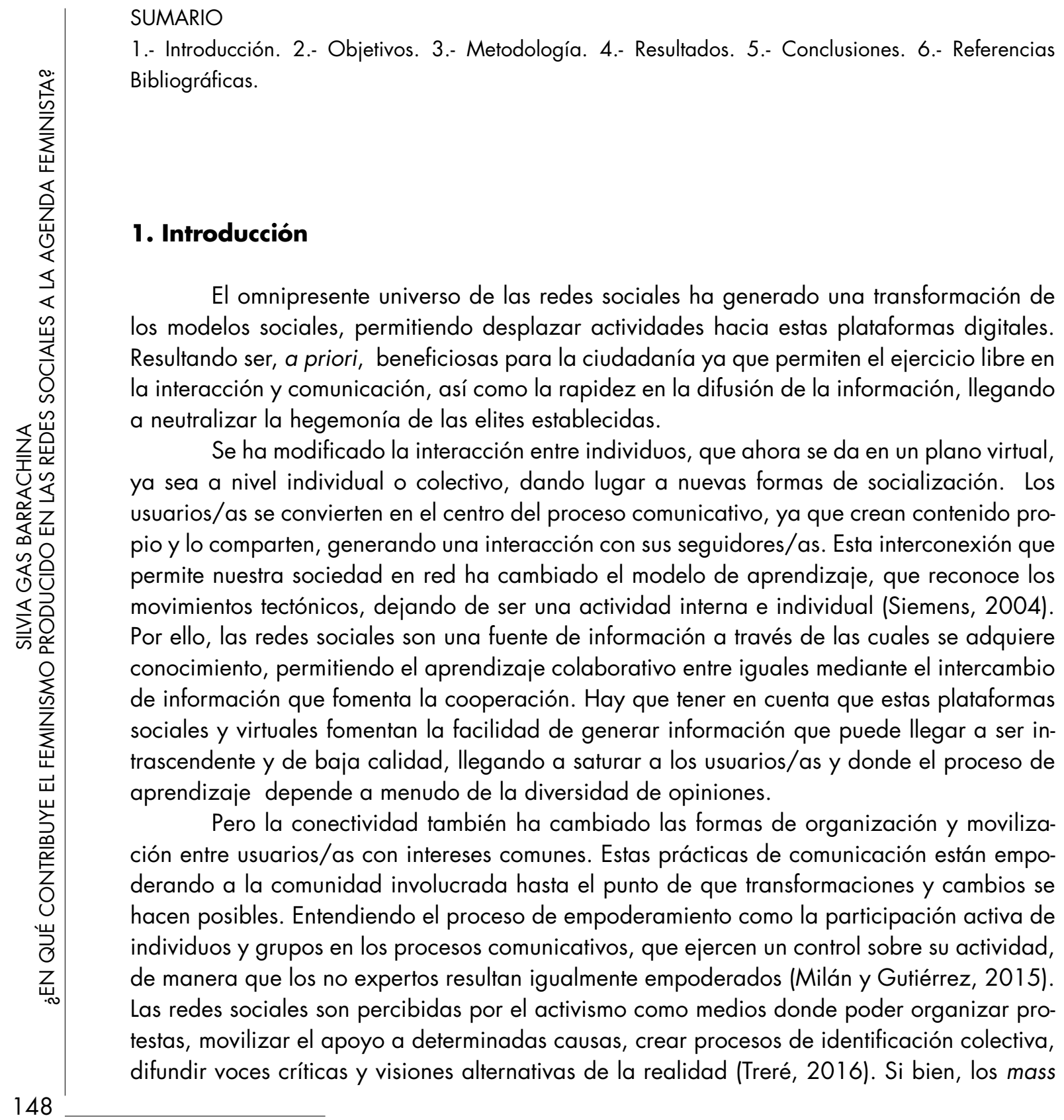

Dossiers Feministes, 25, 2019, 147-167 - ISSN: $1139-1219$ - e-ISSN: 2340-4930 - DOI: http://dx.doi.org/10.6035/Dossiers.2019.25.10 
media han ejercido un dominio sobre la visibilidad y control de la información, ahora, debido al impulso de las redes sociales la hegemonía es fragmentada a favor de la pluralidad. A través de las redes sociales los individuos permanecen conectados, comunicados. Permiten el desarrollo de nuevos aprendizajes debido a la diversidad de información creando un espacio de encuentro, de activismo, que permita una redefinición del ejercicio de poder.

El movimiento feminista intuyó que los espacios virtuales, previos a las redes sociales, son lugares de encuentro y reflexión donde establecer interrelaciones entre semejantes, generar estrategias de resistencia en tanto su capacidad de acción y difundir la agencia feminista. El ciberfeminismo nacido durante la primera época de Internet permitió establecer relaciones de comunicación y participación más libres, así como la configuración de identidades, al margen de condicionantes infundidos por el discurso neoliberal, a los que se someten hoy las redes sociales.

Las redes sociales poseen una estructura egocéntrica donde el contenido y los contactos se estructuran en torno a un usuario/a y no a un tema. Esto es debido fundamentalmente, y aquí radicaría su éxito, a la necesidad del sujeto contemporáneo de ser reconocido por el otro. Los usuarios/as muestran una identidad distorsionada, basada en las apariencias, con el objetivo de agradar y adquirir gratitud de la comunidad virtual (followers, likes, favoritos, retuits, trending topic). En este sentido, se produce un efecto espejo, en el cual los sujetos imitan tanto comportamientos como aspectos formales de aquellos que más reconocimiento obtienen. Se advierte una identidad individualista, basada en la competencia por adquirir reconocimiento.

El espacio virtual se ha transformado del anonimato a la visibilidad. Esto es debido a que estas plataformas ofrecen completar sus perfiles con datos personales, con el fin de hacer un uso comercial de ellos. Los dueños de plataformas sociales han determinado la venta de datos para construir perfiles de consumo como el interés central de su modelo de negocio (Fuchs y Sevignani, 2013). Se mercantiliza la identidad basada en la subjetividad del usuario/a. Como señala Alice Marwick (2010:156): «los medios sociales constituyen tecnologías de subjetividad que enseñan a la gente cómo convertirse en un sujeto apropiado a través de la adopción de la posición deseada». Los usuarios/as con el fin de obtener reconocimiento copian actitudes y temáticas. Para ello, las plataformas crean mediante algoritmos un sistema de visibilidad/invisibilidad donde enseñan $u$ ocultan la información en la línea de tiempo, en función de las tendencias del momento. Se pretende, por parte de los sujetos, alcanzar ser tendencia en base a la imitación y competición con otros y, por parte de las grandes corporaciones, poder comercializar con la actividad de usuarios/as convirtiendo de esta manera las redes sociales en espacios comercializados. 
Las redes sociales son útiles para el movimiento feminista puesto que devienen en un espacio de empoderamiento debido a su rapidez en la transmisión de la información, la facilidad de interacción entre individuos que comparten un eje común, la capacidad de organización y de asimilar información mediante diferentes modelos de aprendizaje. Pero, a pesar de los beneficios que presentan, nos enfrentamos a la problemática de que las redes sociales están atravesadas por la lógica neoliberal, debido a que promueven condicionantes específicos de este sistema como el individualismo, la mercantilización de la identidad subjetiva, la necesidad de reconocimiento o la competencia por ser viral. En este sentido, es necesario reflexionar y verificar mediante este estudio, de carácter empírico, en qué medida el movimiento feminista que se produce en las redes sociales está infundido por las particularidades propias del neoliberalismo.

\section{Objetivos}

En base a la capacidad que poseen los medios sociales para la organización y transmisión de conocimiento siendo de gran utilidad para los movimientos, en este caso concreto para el feminismo, ya que favorece la interseccionalidad y, teniendo en cuenta los condicionantes de las redes sociales sujetos al sistema neoliberal, cabe reflexionar acerca de la relación entre feminismo y redes sociales. Así, surge el objetivo principal de este trabajo, el cual consiste en estudiar los efectos que produce el feminismo desarrollado en las redes sociales en la agencia feminista. Para ello, se pretende:

1) Examinar los usos comunicativos empleados por las redes sociales, en tanto su utilidad y coherencia para el movimiento feminista.

2) Analizar qué tipo de feminismo se genera en estas plataformas virtuales, ya que influirá en la concepción sostenida, sobre todo, por la generación más joven acerca del feminismo.

\section{Metodología}

La metodología empleada responde a una combinación del método cuantitativo y cualitativo. En primer lugar, tomando como base el estudio de redes sociales de 2018 que realiza IAB Spain anualmente se esclarece: 
Un $85 \%$ de internautas entre 16-65 años hacen uso de las redes sociales, lo que significa más de 25,5 millones de personas en nuestro país. De la totalidad, el $51 \%$ son mujeres y $49 \%$ hombres. En cuanto a la edad de usuarios el $31 \%$ se sitúa entre los 16-30 años, el 39\% entre los $31-45$ años y el $30 \%$ entre $46-65$ años, deduciendo una media de 38,4 años. Por tanto, son las mujeres quienes, en un porcentaje ligeramente superior, hacen más uso de las redes sociales. A pesar que comúnmente las redes sociales se relacionan con generaciones más jóvenes el perfil de usuarios comprende una edad entre 31-45 años. Pero si atendemos a la frecuencia de uso son las mujeres y los más jóvenes quienes más tiempo dedican a las redes sociales.

\section{b) Uso de redes sociales}

Facebook es la red más usada en un $87 \%$ aunque, respecto al año pasado, ha perdido popularidad entre usuarios/as. Seguida de Youtube con un $69 \%$ de usuarios/as e Instagram con un $49 \%$. Esta última ha aumentado respecto al año pasado en un $5 \%$ de usuarios/as. En cuanto a las actividades realizadas destacan: ver videos (56\%), ver que hacen mis contactos (44\%), adquirir conocimiento $(36 \%)$ y publicar contenido (33\%).

Una vez delimitadas las redes sociales que se van a analizar (Facebook, Youtube, Instagram) se procede a una investigación de campo. A través de la búsqueda en Internet, mediante un tipo de muestreo no probabilístico, conocido como bola de nieve, se localizan perfiles y usuarios/as que tengan relación con el feminismo. Mediante la observación de su perfil, se identifican otros usuarios/as con rasgos de interés similares. El proceso selectivo para determinar una muestra representativa se ha realizado mediante un análisis de contenido basado en dos criterios concretos: a) perfiles cuyo eje principal sea el feminismo b) número de seguidores, debido a su impacto mediático. El resultado de las variables aplicadas da lugar a una selección de muestras para ser analizadas que corresponden a los siguientes perfiles: 
Tabla 1: Listado páginas feministas de Facebook más populares en España

\begin{tabular}{|c|c|c|c|}
\hline $\begin{array}{l}\text { Nombre } \\
\text { página }\end{array}$ & Seguidores & Tipo de Comunidad & Descripción \\
\hline Freeda Es & 921.884 & $\begin{array}{l}\text { Medio de comunica- } \\
\text { ción/noticias }\end{array}$ & $\begin{array}{l}\text { Empoderamiento femenino, estilo } \\
\text { personal y sororidad. }\end{array}$ \\
\hline Lola & 759.492 & Medio de comunicación & $\begin{array}{l}\text { Feminismo pop de la mano de BuzzFeed } \\
\text { España }\end{array}$ \\
\hline $\begin{array}{l}\text { Moderna } \\
\text { de Pueblo }\end{array}$ & 670.324 & Arte y ocio & $\begin{array}{c}\text { Página de la ilustradora Raquel Cór- } \\
\text { coles, mediante la cual comparte sus } \\
\text { trabajos. }\end{array}$ \\
\hline $\begin{array}{l}\text { Feministas } \\
\text { Siempre }\end{array}$ & 341.463 & Entretenimiento & $\begin{array}{l}\text { Página para la visibilización de las muje- } \\
\text { res y sus logros }\end{array}$ \\
\hline $\begin{array}{l}\text { Feminismo } \\
\text { Radical }\end{array}$ & 277.882 & Entretenimiento & $\begin{array}{c}\text { Somos feministas radicales, abolicio- } \\
\text { nistas, pro-aborto y rechazamos todas } \\
\text { las expresiones religiosas patriarcales y } \\
\text { machistas. }\end{array}$ \\
\hline $\begin{array}{l}\text { Locas Del } \\
\text { Coño }\end{array}$ & 225.082 & Medio de comunicación & $\begin{array}{l}\text { Revista feminista colaborativa digital. } \\
\text { Sororidad como autodefensa feminista. } \\
\text { Si nos tocan a una, nos tocan a todas. }\end{array}$ \\
\hline $\begin{array}{l}\text { Feminista } \\
\text { Ilustrada }\end{array}$ & 179.297 & Arte y ocio & $\begin{array}{l}\text { Trabajo contra el machismo en la so- } \\
\text { ciedad actual a través de la educación } \\
\text { visual, la ironía y el humor. }\end{array}$ \\
\hline $\begin{array}{l}\text { Pikara Ma- } \\
\text { gazine }\end{array}$ & 122.307 & Medio de comunicación & $\begin{array}{l}\text { Revista que ofrece periodismo y opinión } \\
\text { con un enfoque feminista, crítico, trans- } \\
\text { gresor y disfrutón. \#PeriodismoFeminista }\end{array}$ \\
\hline $\begin{array}{l}\text { Barbi Ja- } \\
\text { puta }\end{array}$ & 89.611 & Entretenimiento & $\begin{array}{l}\text { Seudónimo de una escritora y columnista } \\
\text { española. «Soy responsable de lo que } \\
\text { digo, no de lo que tú entiendas». }\end{array}$ \\
\hline $\begin{array}{l}\text { Feminismo } \\
y+\end{array}$ & 77.372 & Entretenimiento & $\begin{array}{l}\text { Feminismoymas es un proyecto que pre- } \\
\text { tende teñir de morado el espíritu ciuda- } \\
\text { dano de la ciudad de Oviedo. }\end{array}$ \\
\hline
\end{tabular}


Tabla 2: Listado canales feministas de Youtube más populares en España

\begin{tabular}{|c|c|c|c|}
\hline $\begin{array}{c}\text { Nombre } \\
\text { página }\end{array}$ & Suscriptores & Visualizaciones & Descripción \\
\hline $\begin{array}{c}\text { BuzzFeed } \\
\text { LOLA }\end{array}$ & 111.478 & 5.424 .281 & $\begin{array}{c}\text { Videos realizados por la periodista Beatriz } \\
\text { Serrano enclavados en su página de Face- } \\
\text { book Lola. }\end{array}$ \\
\hline Asadaf & 26.685 & 846.211 & Youtuber feminista \\
\hline $\begin{array}{c}\text { Psico Wo- } \\
\text { man }\end{array}$ & 11.248 & 630.188 & $\begin{array}{c}\text { Videos realizados por Isa Duque, Psicóloga, } \\
\text { sexóloga y terapeuta sistémica familiar. Con } \\
\text { multitud de formaciones en género, terapias } \\
\text { corporales y herramientas educativas. }\end{array}$ \\
\hline $\begin{array}{c}\text { Canal femi- } \\
\text { nista España }\end{array}$ & 283 & 7.571 & $\begin{array}{c}\text { Espacio informativo en el cual se puede cola- } \\
\text { borar subiendo videos. }\end{array}$ \\
\hline $\begin{array}{c}\text { Towanda } \\
\text { Rebels }\end{array}$ & - & 1.813 .591 & Canal de Teresa Lozano y Zua Méndez. \\
\hline $\begin{array}{c}\text { El Tornillo } \\
\text { Isartvlog }\end{array}$ & 36.568 & 3.290 .217 & $\begin{array}{c}\text { En la sección Damisela en Apuros se habla } \\
\text { acerca de cuestiones feministas. }\end{array}$ \\
\hline $\begin{array}{c}\text { Feminismo } \\
\text { para Torpes }\end{array}$ & -18.636 & $\begin{array}{c}\text { Micro espacio feminista, presentado por Irant- } \\
\text { zu Varela, del programa En la Frontera de } \\
\text { Diario Público. }\end{array}$ \\
\hline
\end{tabular}


Tabla 3: Listado cuentas feministas de Instagram más populares en España

\begin{tabular}{|c|c|c|}
\hline Nombre página & Seguidores & Descripción \\
\hline $\begin{array}{l}\text { @modernadepue- } \\
\text { blo }\end{array}$ & $1,1 \mathrm{~mm}$ & $\begin{array}{c}\text { Cuenta de la ilustradora Raquel Córcoles, mediante la cual } \\
\text { comparte sus trabajos. }\end{array}$ \\
\hline @freeda_es & $539 k$ & $\begin{array}{l}\text { Detrás de una gran mujer siempre hay otras grandes mujeres. } \\
\text { Ellas son las que te revisan los mensajes antes de enviarlos. } \\
\text { \#freeda }\end{array}$ \\
\hline @flavitabanana & $476 k$ & $\begin{array}{c}\text { Cuenta de una viñetista, ilustradora y dibujante española, } \\
\text { mediante la cual comparte sus trabajos. }\end{array}$ \\
\hline @lola.vendetta & $362 k$ & Cuenta oficial del personaje de cómic de Raquel Riba. \\
\hline $\begin{array}{l}\text { @feministailustra- } \\
\text { da }\end{array}$ & $345 k$ & Frases acompañadas de ilustraciones. \\
\hline @eres_una_caca & $140 k$ & $\begin{array}{c}\text { A partir de cacas parlantes denuncia caos de violencia de } \\
\text { género. }\end{array}$ \\
\hline $\begin{array}{l}\text { @machismocalle- } \\
\text { jero }\end{array}$ & $139 k$ & Casos de violencia de género, fotos y convocatorias. \\
\hline $\begin{array}{l}\text { @revolucionfemi- } \\
\text { nista }\end{array}$ & $126 k$ & Viñetas fotos y convocatorias. \\
\hline @zinteta & $94,7 \mathrm{k}$ & $\begin{array}{c}\text { Cuenta de la artista Cinta Tort Cartró, mediante la cual com- } \\
\text { parte sus trabajos. }\end{array}$ \\
\hline @buzzfeedlola & $80,4 k$ & Quererte a ti misma es revolucionario. \\
\hline
\end{tabular}

Determinada la muestra, se procede al estudio de los usos comunicativos donde se analiza de cada perfil: a) Por parte del emisor, la actividad de la cuenta mediante el número y frecuencia de publicaciones, b) Respecto al mensaje, si se genera contenido propio o se copian enlaces de otros canales, los recursos empleados en cada mensaje y las temáticas más utilizadas, c) Sobre el receptor, se analiza la popularidad del canal, la participación y 154 la viralidad. 
Debido a la abundante actividad que presentan las redes sociales se han analizado únicamente los mensajes publicados en el mes de enero, excepto en Youtube ya que, por su forma de presentar la información a través de videos, lo que supone un trabajo más costoso y por tanto no son tan abundantes las publicaciones, se han analizado aquellos videos que estuvieran relacionados con la temática estudiada.

Finalmente, una vez recabada la información, se aplica el método sistemático. Mediante la interpretación se relacionan elementos y estrategias diversas en una teoría unificadora que permite, como resultado, identificar en qué modo estas plataformas virtuales intervienen y contribuyen al movimiento feminista.

\section{Resultados}

Los resultados obtenidos muestran que Facebook es la red social con mayor número de páginas centradas en el feminismo, donde se genera y comparte información y mediante los comentarios se discute acerca de las publicaciones. En Instagram no se han encontrado cuentas dedicadas exclusivamente al feminismo al margen de los portales virales que comparten cuentas en todas las redes sociales. En cambio, se observa una amplia mayoría de cuentas de artistas que comparten sus trabajos con una perspectiva de género. Esto es debido a que la imagen y no el texto es el recurso principal de esta red social y, por tanto, se dificulta la producción y discusión de temas. Por otro lado, al estar fundamentada en la fotografía y la autorepresentación, permite la reflexión a través de la imagen sobre los diferentes discursos y lenguajes emancipadores que las mujeres utilizan para desarticular sociedades patriarcales y reafirmarse como sujetos. En nuestra sociedad, basada en la estética y en el consumo acelerado, las personas nos comunicamos y adquirimos información de forma más rápida visualmente que a través del texto, dotando a las imágenes de un poder discursivo. Youtube es la red social que menos canales dedica al feminismo, a causa de que el video es la vía principal de comunicación. Este hecho supone que una persona se descubre frente a una cámara explicando sus ideas, mostrándose vulnerable, exponiéndose, en consecuencia, al juicio de aquellos que contemplan. Y así se observa en los comentarios de los videos, en su mayoría negativos y poco constructivos, que difaman acerca de la persona que aparece en la imagen. Por ello, algunos canales deciden desactivar la opción por parte de usuarios/as de realizar comentarios. No se han encontrado canales de Youtube dedicados exclusivamente al feminismo. El Tornillo y Feminismo para Torpes son microespacios de los periódicos El Diario Público y El País respectivamente, que acercan el feminismo a la ciudadanía mediante la voz de una periodista formada en cuestiones de género. Por otro lado, se encuentran numerosas youtubers 
que dedican esporádicamente espacios a hablar sobre feminismo, excepto Asadaf, en el que su canal prácticamente está dedicado a comentar cuestiones sobre género cercanas a ella, 0 Isartvlog, que dedica un espacio llamado Damisela en Apuros a hablar sobre feminismo. En este sentido es necesario reflexionar acerca de las youtubers. Son jóvenes interesadas en las cuestiones feministas y que tienen mucha influencia en la población joven, el problema reside que muchas de ellas no están formadas en estas cuestiones y en consecuencia pueden llegar a confundir. Sí que encontramos dos canales, Psico Woman y Towanda Rebelds, que están destinados exclusivamente a informar desde una perspectiva de género.

Debido a que Facebook es la red social más usada y a su vez más vinculada al feminismo, se examinarán de forma más exhaustiva respecto al resto de redes sociales (Instagram, Youtube) los usos comunicativos de estas páginas.

\section{a) Emisor}

Gráfico 1: Porcentaje publicaciones en el mes de enero páginas de Facebook

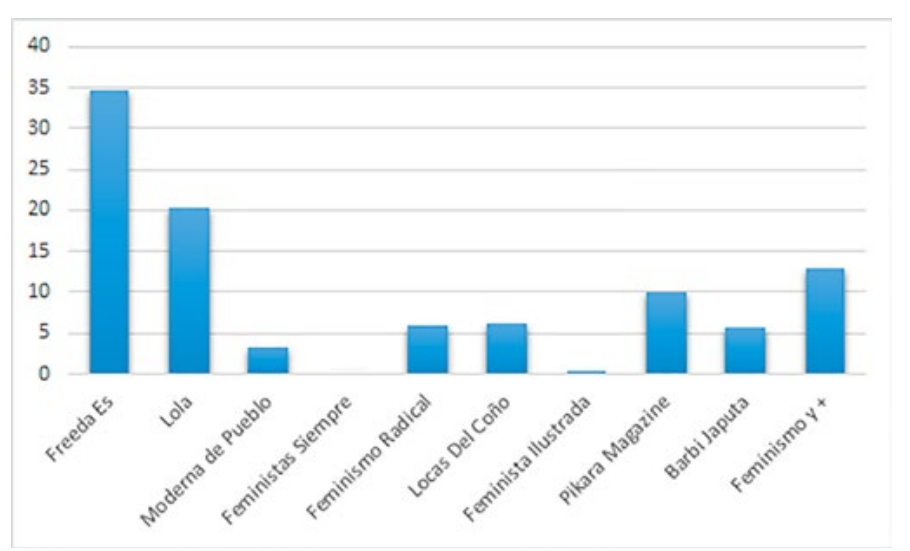

Como se representa en el gráfico, los resultados obtenidos muestran que la página de Facebook Freeda ES es la que más frecuencia de actividad presenta, con un total de 155 publicaciones en enero, seguida de Lola y Feminismoy+. La página con menos publicaciones es Feminista llustrada y Moderna de Pueblo con 2 y 15 entradas publicadas respectivamente. Hay que destacar que Feministas Siempre no ha notificado ninguna publicación en el mes de enero, siendo los últimos post del mes de agosto; en consecuencia, no se ha podido realizar el análisis sobre esta página de Facebook. 
Se aprecia una correlación entre aquellas páginas con un número superior de seguidores y una mayor frecuencia de actividad, es decir, a más seguidores más mensajes publicados. Aunque se observan algunas excepciones, como la página Moderna de Pueblo, situada en tercera posición en número de seguidores pero que muestra, en cambio, poca frecuencia de actividad. En contra, páginas con más frecuencia de actividad, como Pikara - Feminismoy+, tienen menos seguidores. Estos indicadores muestran los intereses de los usuarios. Las páginas de Facebook con más seguidores, Freeda ES y Lola ${ }^{1}$, corresponden a portales de creación de contenido viral que hacen uso de las redes sociales para difundir su mensaje. Estas páginas generan gran cantidad de contenido, llegando a las cinco o seis publicaciones al día, hecho que influirá en la tipología y calidad del mensaje, con el fin de captar a usuario/as que buscan distracción antes que información.

Gráfico 2: Porcentaje publicaciones en el mes de enero cuentas Instagram

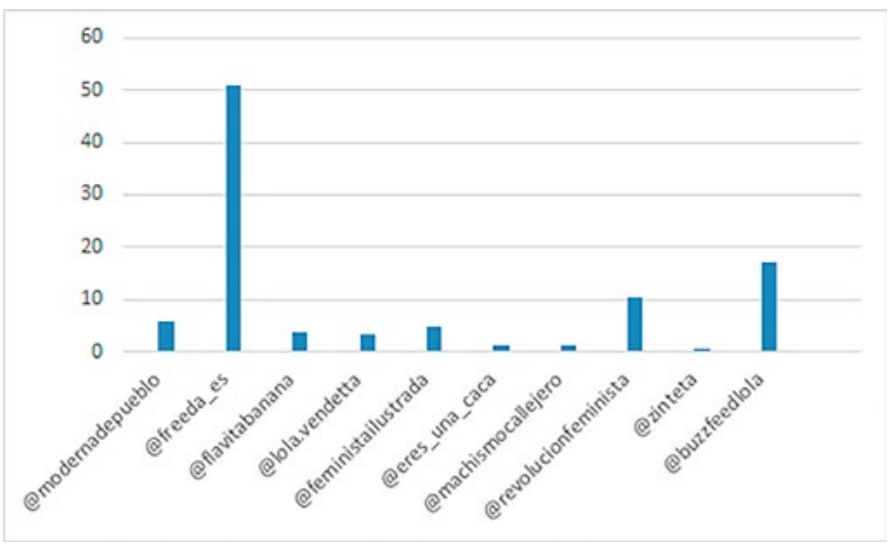

Como se observa en el gráfico 2, las cuentas de Instagram con más frecuencia de actividad corresponden del mismo modo que en Facebook a aquellas que crean contenido viral. En cambio, las cuentas de artistas que muestran sus trabajos a través de estas cuentas presentan una menor frecuencia de publicaciones.

$\overline{1}$ A finales de enero de 2019 se anunció el cierre del portal Buzfeed y Buzfeedlola en España a causa de numerosos despidos. 
En cuanto a la relación con el número de seguidores, se observa que las páginas que crean contenido viral se sitúan en segundo y último lugar. Por ejemplo, si se compara con Facebook, la cuenta de Lola permanece en último lugar a pesar de publicar con mayor frecuencia. En cambio, las cuentas que comparten el trabajo realizado por las usuarias tienen mayor número de seguidores. Se percibe, a diferencia de Facebook, que en Instagram no se busca información sobre feminismo sino la contemplación y valoración de trabajos relacionados con perspectiva de género.

\section{Gráfico 3: Porcentaje publicaciones en los canales de Youtube}

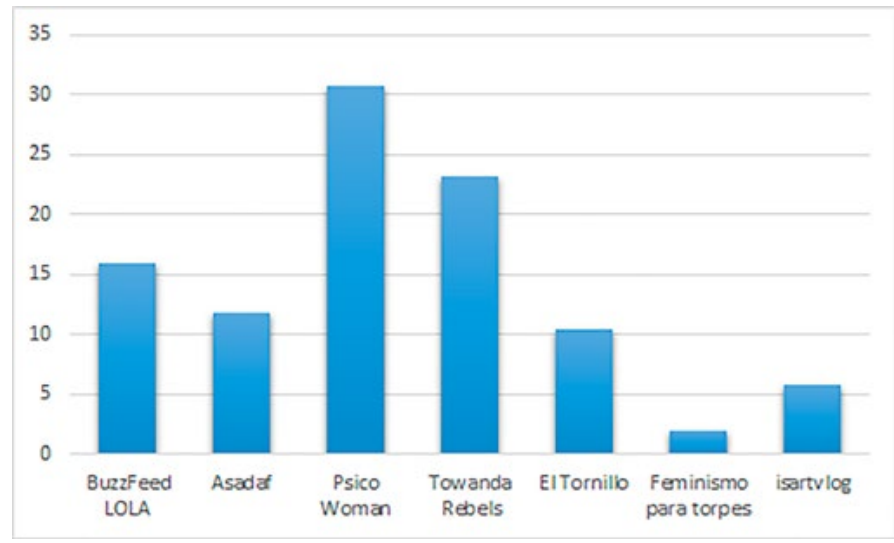

En Youtube, es destacable cómo los canales que proporcionan información acerca del feminismo publican con más frecuencia que el resto. Este hecho es interesante puesto que no ocurre ni en Facebook ni en Instagram. A pesar de que en Youtube es menor la presencia de canales feministas, se observa un mayor compromiso de los pocos canales existentes.

\section{b) Mensaje}

Respecto al análisis del mensaje, se observa de qué forma la mayoría de las páginas de Facebook comparten información externa en mayor o menor cantidad. En cambio, algunas generan contenido propio. Freeda Es y Lola comparten mensajes, $60 \%$ y $56 \%$ respectivamente de la totalidad, enlazados a escritos propios publicados en su web. Igual que Pikara, con el $69 \%$ de mensajes sobre artículos enlazados a su revista digital. Aunque se observa una diferencia en la temática y modelo del mensaje. Si bien Pikara al ser una revista feminista 
presenta artículos de calidad periodística, Freeda Es y Lola muestran información relacionada, más que con el movimiento feminista, con las mujeres como eje central del mensaje mediante rasgos de humor social sin ese carácter formal que requiere un texto periodístico. Moderna de Pueblo genera únicamente contenido propio mediante la publicación de sus dibujos, por esta razón el número de publicaciones es inferior al resto de páginas. Barbilaputa cuenta con el 93\% de mensajes propios que promocionan el contenido que genera, o bien a través de podcast en la radio o mediante artículos que ella misma escribe en El Diario.

Gráfico 4: Porcentaje recursos más usados en Facebook

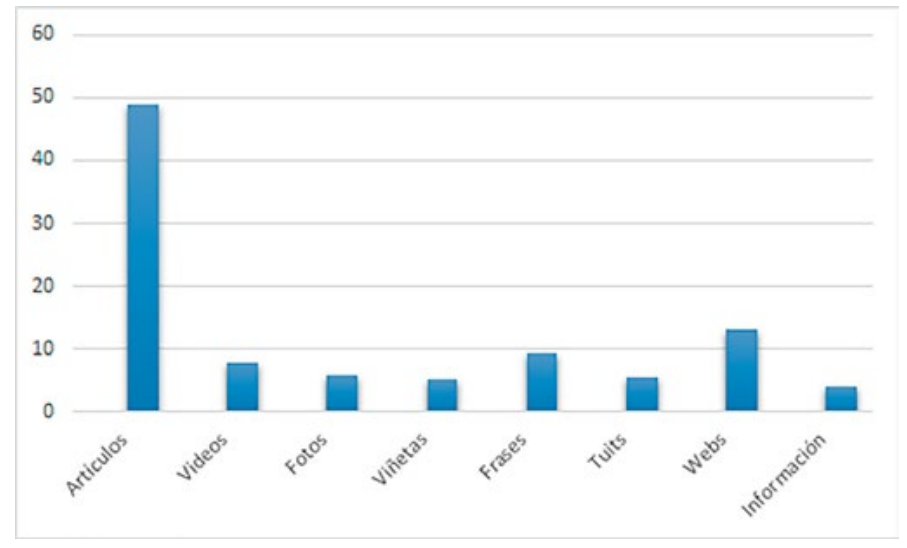

Los recursos empleados a la hora de presentar la información, son en su mayoría artículos propios o compartidos de otros diarios, con un porcentaje total del $48,8 \%$, seguido de webs informativas con un $13 \%$ y frases feministas con un $9,3 \%$. Los recursos menos utilizados son compartir información (conciertos, convocatorias...) con un 4,1\% y viñetas, fotos y capturas de tuits se sitúan bastante igualados en un margen del $5 \%$. Estos resultados nos muestran que la función principal de estas páginas es o bien compartir noticias relevantes en torno a cuestiones de género o promocionar su contenido propio para captar seguidores.

Estas noticias son compartidas a través de plataformas como Elmundo.es, Eldiario.es, Lasexta.com, Elperiodico.com, Público.es y Elpais.com, cuyas temáticas responden a casos de asesinatos machistas, conciliación vida laboral y maternidad, análisis de mujeres feministas, ejemplos concretos de desigualdades entre hombres y mujeres y el caso de "La manada". 
En cambio, las páginas que generan contenido propio, como Freeda Es y Lola, presentan información dispar acerca de cuestiones que giran en torno a las mujeres.

En Instagram las publicaciones, tal y como se ha citado con anterioridad, corresponden a imágenes del trabajo de las artistas. Las cuentas que tienen redes sociales en Facebook e Instagram, como@modernadepueblo, @freeda_es o @buzzfeedlola, comparten las mismas publicaciones en ambas plataformas. En este sentido, el mensaje de carácter feminista se difunde mediante ilustraciones o imágenes artísticas que son asimiladas con rapidez y facilidad por los seguidores/as. Aunque aquí el mensaje es de carácter subjetivo y parte de la perspectiva del yo, de la posición de la artista respecto a la sociedad.

En Youtube el mensaje es directo, sin menor oscilación en la interpretación y llega directamente al espectador. Uno de los recursos más usados a la hora de transmitir la información es a través de la ironía y/o el humor. Cabe destacar que los dos canales de youtubers, Asadaf e Isartvlog, difunden su mensaje a partir de su propia experiencia, de modo que tratan temas cercanos a ellas.

c) Receptor

En cuanto a la implicación de los seguidores/as se establece una relación: aquellas páginas de Facebook con más seguidores/as serán las que obtengan mayor respuesta. Así, Freeda Es y Lola siguen siendo las que más feedback reciben.

Resulta interesante analizar cuáles han sido los mensajes que más respuestas han generado. Se contempla una diferencia entre aquellos mensajes populares, aquellos que reciben más «me gusta», los que reciben más comentarios, que hacen referencia a la participación de los seguidores y los mensajes más virales, aquellos que se comparten.

Los mensajes más populares son de carácter distendido, que provocan gracia al espectador o con los cuales se siente identificado. Por ejemplo, se observa que los mensajes que más «me gusta» reciben son los que se relacionan con frases referentes a la libertad de las mujeres y no tanto con noticias compartidas de periódicos.

Las publicaciones que comentan los seguidores/as son, por un lado, aquellas de carácter lúdico o relajado con las que se sienten identificados/as y, por otro, publicaciones que suscitan controversia con temática polémica en cuyos comentarios se genera un debate. También ocurre con las publicaciones compartidas que responden a temas de actualidad o con los que se sienten identificadas. 
Tabla 4: Listado de cuentas feministas de Facebook y los temas con mayor popularidad, participación y viralidad

\begin{tabular}{|c|c|c|c|}
\hline $\begin{array}{l}\text { Nombre } \\
\text { página }\end{array}$ & Me Gusta & Comentarios & Compartido \\
\hline Lola & $\begin{array}{l}\text { Video: } \\
\text { Serie de Nefflix } \\
\text { Sex Education } \\
\text { «lt's my vagina» }\end{array}$ & $\begin{array}{c}\text { Video: } \\
\text { Chica en la playa dando vol- } \\
\text { teretas } \\
\text { «Tía no te rayes» }\end{array}$ & $\begin{array}{l}\text { Frase acompañada del dibujo } \\
\text { de Lisa Simpson: } \\
\text { «Respetar solo a las mujeres } \\
\text { por las que te sientes atraído } \\
\text { no es respetar a las mujeres» }\end{array}$ \\
\hline $\begin{array}{l}\text { Feminismo } \\
\text { Radical }\end{array}$ & $\begin{array}{c}\text { Frase: } \\
\text { «Hay mujeres que se sienten } \\
\text { realizadas al ser madres, } \\
\text { otras al encontrar a alguien } \\
\text { con quien compartir su vida } \\
\text { otras con tres títulos univer- } \\
\text { sitarios y otras viajando. } \\
\text { ¿Tan difícil es entender que } \\
\text { no todas aspiramos a lo } \\
\text { mismo?» }\end{array}$ & $\begin{array}{l}\text { Frase: } \\
\text { «Muchos hombres se creen } \\
\text { buenos porque jamás han } \\
\text { golpeado a una mujer no hace } \\
\text { falta golpear para hacer daño, } \\
\text { la infidelidad duele, los insultos } \\
\text { duelen, el silencio duele, las } \\
\text { mentiras duelen, no hay nada } \\
\text { más peligroso que un hombre } \\
\text { cruel fingiendo ser buena per- } \\
\text { sona» }\end{array}$ & $\begin{array}{l}\text { Frase: } \\
\text { «Hay mujeres que se sienten } \\
\text { realizadas al ser madres, } \\
\text { otras al encontrar a alguien } \\
\text { con quien compartir su vida } \\
\text { otras con tres títulos universita- } \\
\text { rios y otras viajando. } \dot{2}^{\text {Tan di- }} \\
\text { fícil es entender que no todas } \\
\text { aspiramos a lo mismo?» }\end{array}$ \\
\hline $\begin{array}{l}\text { Locas Del } \\
\text { Coño }\end{array}$ & $\begin{array}{l}\text { Noticia compartida cultura- } \\
\text { inquieta.com: Manifestación } \\
\text { en Londres cuestiona los } \\
\text { ideales de belleza. }\end{array}$ & $\begin{array}{c}\text { Video: } \\
\text { Acerca del racismo }\end{array}$ & $\begin{array}{c}\text { Video: } \\
\text { Acerca del racismo }\end{array}$ \\
\hline $\begin{array}{l}\text { Feminista } \\
\text { Ilustrada }\end{array}$ & $\begin{array}{c}\text { Frase: } \\
\text { «Si todavía no sabes por } \\
\text { qué a las mujeres nos cuesta } \\
\text { tanto contar las agresiones } \\
\text { que hemos sufrido solo tie- } \\
\text { nes que contar las veces que } \\
\text { han dudado de nosotras» }\end{array}$ & $\begin{array}{c}\text { Frase: } \\
\text { «Si todavía no sabes por qué } \\
\text { a las mujeres nos cuesta tanto } \\
\text { contar las agresiones que } \\
\text { hemos sufrido solo tienes que } \\
\text { contar las veces que han duda- } \\
\text { do de nosotras» }\end{array}$ & $\begin{array}{c}\text { Frase: } \\
\text { «Si todavía no sabes por } \\
\text { qué a las mujeres nos cuesta } \\
\text { tanto contar las agresiones } \\
\text { que hemos sufrido solo tienes } \\
\text { que contar las veces que han } \\
\text { dudado de nosotras» }\end{array}$ \\
\hline $\begin{array}{c}\text { Pikara } \\
\text { Magazine }\end{array}$ & $\begin{array}{c}\text { Meme: } \\
\text { Acerca de la regla }\end{array}$ & $\begin{array}{c}\text { Meme: } \\
\text { Acerca de la regla }\end{array}$ & $\begin{array}{l}\text { Entrevista: } \\
\text { Sanjuana Martínez es una pe- } \\
\text { riodista amenazada de muerte } \\
\text { por investigar la pederastia } \\
\text { clerical. Tiene mucho que } \\
\text { contar sobre los Legionarios } \\
\text { de Cristo, una de las congre- } \\
\text { gaciones más poderosas e } \\
\text { influyentes dentro de la lglesia } \\
\text { católica y fuera de ella. }\end{array}$ \\
\hline
\end{tabular}




\begin{tabular}{|c|c|c|c|c|}
\hline 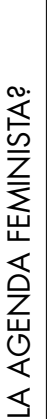 & $\begin{array}{l}\text { Barbi Ja- } \\
\text { puta }\end{array}$ & $\begin{array}{c}\text { Noticia compartida del } \\
\text { periodico.com: } \\
\text { Imputado por difundir datos } \\
\text { de la víctima de 'La mana- } \\
\text { da' } \\
\text { Un barcelonés declara ante } \\
\text { el juez por haber reprodu- } \\
\text { cido la información en una } \\
\text { página de internet }\end{array}$ & $\begin{array}{l}\text { Post: } \\
\text { Esta es la presidenta de Vox en } \\
\text { Albacete. } \\
\text { También tiene tuits donde ex- } \\
\text { pone a compañeras mostrando } \\
\text { fotos de cómo no se depilan, } \\
\text { generando contra ellas una } \\
\text { avalancha de comentarios ma- } \\
\text { chistas como "puta", "guarra", } \\
\text { "cerda", "feminazi". } \\
\text { Por favor, votemos en las elec- } \\
\text { ciones. Votemos TODAS. }\end{array}$ & $\begin{array}{l}\text { Noticia compartida eldiario. } \\
\text { es: } \\
\text { Listado de propuestas de vox }\end{array}$ \\
\hline $\begin{array}{l}\varangle \\
\dddot{u} \\
\frac{1}{U}\end{array}$ & $\begin{array}{c}\text { Feminismo } \\
y+\end{array}$ & $\begin{array}{c}\text { Tuit: } \\
\text { «He puesto a Siri voz } \\
\text { masculina y se ha puesto a } \\
\text { explicarme cosas sin pre- } \\
\text { guntarle nada» }\end{array}$ & $\begin{array}{l}\text { Tuit: } \\
\text { «He puesto a Siri voz masculina } \\
\text { y se ha puesto a explicarme } \\
\text { cosas sin preguntarle nada» }\end{array}$ & $\begin{array}{c}\text { Viñeta: } \\
\text { Se representa a un padre } \\
\text { aconsejando a su hijo que } \\
\text { deje en paz a la niña que } \\
\text { le gusta porque a ella no le } \\
\text { gusta él. }\end{array}$ \\
\hline
\end{tabular}

En Instagram las publicaciones más populares corresponden del mismo modo que en Facebook a ilustraciones mediante las cuales seguidores/as se sienten identificadas. En cambio, los altos niveles de popularidad y participación que se generan con más constancia en Facebook que en Instagram disminuyen notablemente en los canales de Youtube, llegando a ser reiteradamente comentarios negativos.

\section{Conclusiones}

La estabilización de las redes sociales en nuestra sociedad pone de manifiesto la necesidad de reflexionar acerca de la innegable correlación existente entre la web social y el movimiento feminista. El análisis de los resultados obtenidos manifiesta la falta de páginas/cuentas o canales cuyo eje central sea el feminismo. Si bien es cierto que encontramos algunas cuya base es exclusivamente feminista no son necesarias si tenemos en cuenta la repercusión de las redes sociales en nuestra sociedad. ¿2Por qué esta falta de redes sociales basadas en el feminismo? $\mathrm{Si}$ atendemos a los resultados obtenidos se evidencia que la falta de conocimientos acerca del feminismo por parte de usuarios/as radicaría en la razón principal de esta ausencia. Además, de la necesidad por parte del sujeto de compartir contenido que agrade a los usuarios/as para recibir feedback y, así, llegar a ser viral.

La interconexión en red ha permitido que las redes sociales sean un instrumento para el aprendizaje colaborativo, por ello la difusión del movimiento feminista a través de estas 
plataformas virtuales y sociales se torna indispensable para expandir la información y educar desde una perspectiva de género a sujetos ajenos al feminismo. Además, posibilitan modos de organización y movilización empoderando a la comunidad, visibilizando prácticas alternas a la hegemonía dominante que favorecen las transformaciones. Pero, según muestran los resultados, lejos de usar las redes sociales como lugar común para el debate feminista y su consiguiente difusión, son más bien usadas como lugares de entretenimiento.

Este estudio constata que Facebook es la red social con mayor difusión de información acerca del feminismo. Esto ocurre, en primer lugar, porque es la red social más usada, como así demuestra el estudio de redes sociales que realiza IAB Spain anualmente. En segundo lugar, por su método de funcionamiento basado en la combinación de texto e imagen, hecho que facilita la difusión de información permitiendo, además, compartir enlaces de otras webs. En cambio Youtube es el medio con menor uso debido principalmente a su método de funcionamiento basado exclusivamente en el video. En consecuencia la información es transmitida mediante la voz encarnada en la identidad de un individuo que se expone al juicio público de aquellos/as que contemplan. Por otro lado, Instagram es utilizada en su mayoría por artistas que difunden sus trabajos con una perspectiva de género, ya que la imagen es la herramienta principal de funcionamiento de esta red social.

Respecto a los usos comunicativos analizados sobre las tres redes sociales (Facebook, Youtube, Instagram) se certifica que las páginas que generan contenido viral son aquellas que tienen más seguidores; por el contrario, aquellas que poseen una sólida base feminista tienen menos seguidores. La causa reside esencialmente en que los/as usuarios/as acuden a las redes sociales como forma de distracción y no para adquirir consecuentemente conocimientos, a pesar que consciente $o$ inconscientemente las redes sociales nos instruyen y nos forman en juicios concretos. Por tanto, es necesario reflexionar acerca del contenido que difunden estas páginas virales y que se consideran feministas. En numerosas ocasiones se ha observado como los mensajes publicados se relacionan con asuntos adscritos a la condición femenina más que con el feminismo como movimiento, generando de esta forma confusión entre los seguidores/as. Por contra, cuando se publican asuntos considerados propios de la cuestión feminista se genera un debate y muchas de las reacciones observadas son negativas. En este sentido las redes sociales evidencian y plasman la confusión existente entre la sociedad sobre el movimiento feminista. Sobre el mensaje se contempla, además, que la mayoría de publicaciones se realizan mediante recursos compartidos y pocas páginas generan contenido propio. Asimismo, aquellas publicaciones que suscitan más interés son aquellas que apenas están relacionadas con cuestiones feministas. 
A pesar de que las redes sociales se entienden como espacios colectivos y horizontales, donde movimientos sociales, en concreto el feminismo, hacen uso para manifestarse poniendo en común diferentes voces y creando alianzas, en tanto su capacidad de encuentro, los condicionantes propios del neoliberalismo que atraviesan las redes sociales lo imposibilitan. Como se ha analizado, el feminismo producido en las redes sociales estudiadas parte de una identidad subjetiva de carácter individualista donde prima el reconocimiento. Las páginas consideradas feministas responden a un carácter comercial en favor a una lucha por la viralidad. Por ello, las páginas de contenido viral son las que tienen más seguidores, del mismo modo que las publicaciones virales son las que más debate generan. En consecuencia, el feminismo que se sucede en las redes sociales responde a un feminismo mainstream fundamentado en una visión sesgada en torno al yo y su mercantilización, alejado de la posibilidad de generar un movimiento con una base sólida y común. Como resultado, las redes sociales difunden un feminismo que enfatiza las diferencias, falto de pluralidad y unión, creando confusión entre la sociedad y suscitando confrontaciones.

No obstante, las redes sociales han constituido un medio importante en la visibilización y difusión del movimiento feminista en la sociedad, quebrando el dominio de los mass media que silenció el feminismo. Podríamos deducir, a pesar de los condicionantes expuestos en este trabajo y del arduo trabajo que aún queda por realizar, que debido a las redes sociales la palabra feminismo es pronunciada por la voz pública.

\section{Referencias bibliográficas}

BECK, Ulrich y Elisabeth BECK-GERNSHEIM, (2003). La individualización. El individualismo institucionalizado y sus consecuencias sociales y políticas, Barcelona: Paidós.

BOIX, Montserrat; FRAGA, Cristina y Victoria SEDÓN (2001). «El viaje de las internautas. Una mirada de género a las nuevas tecnologías», en Género y Comunicación, Red Internacional de Mujeres de la Comunicación, AMECO. Disponible en: http://www.mujeresenred. net/el_viaje_de_las_internautas.html (Fecha de consulta: 20/01/2019).

BONAVITTA, Paola; DE GARAY, Jimena y Jeli Edith CAMACHO, (2015). «Mujeres, feminismos y redes sociales: acceso, censura y potencialización» en Questión, Nº48, pp. 33-44.

BOSCH, Anna (2005). «Feminismo, nuevos paradigmas y acción gubernamental» en IBARRA, Pedro y Elena GRAU (eds.) (2005). La política en la red: anuario de movimientos sociales, Barcelona: Icaria, pp. 209-219.

164

Dossiers Feministes, 25, 2019, 147-167 - ISSN: $1139-1219$ - e-ISSN: 2340-4930 - DOI: http://dx.doi.org/10.6035/Dossiers.2019.25.10 
BOYD, Danah y Nicole Eluson (2008). «Social Network Sites: Definition, History, and Scholarship» en Journal of Computer-Mediated Communication, N¹3, pp. 210-230.

CARO, Lucia (2015). "Construir y comunicar un "nosotras" feminista desde los medios sociales. Una reflexión acerca del "feminismo del hashtag"» en Commons Revista de Comunicación y Ciudadanía digital, № 2, pp. 124-154.

CASERO, Andreu (2017). «Producing political content for web 2.0: Empowering citizens and vulnerable populations» en El Profesional de la Información, №1, pp. 13-19.

CASTells, Manuel (2009). Comunicación y poder, Madrid: Alianza.

CHRISTAKIS, Nicholas y James FOWLER (2010). Conectados. El sorprendente poder de las redes sociales y cómo nos afectan, Madrid: Taurus.

DE MIGUel, Ana y Montserrat BOIX (2002). «Los géneros de la red: los ciberfeminismos. El ciberfeminismo social», en The Role of Humanity in the Information Age. A Latin Perspective, Disponible en: http://www.mujeresenred.net/spip.php?article297 (Fecha de consulta: 13/12/2018).

ETURA, Dunia; GUTIÉRREZ, Víctor y Virginia MARTín (2017). «La cultura mediática y el discurso posmachista: análisis retórico de Facebook ante la violencia de género» en Investigaciones Feministas, Vol.8, №2, pp. 369-384.

FERNÁNDEZ, Diana; CORREDOR, Patricia y Marina SANTín (2011). "Nuevos espacios de comunicación, relación y activismo en la era digital: la Red como oportunidad para el feminismo» en Asparkía, № 22, pp. 61-72.

FOtopoulou, Aristea (2014). "Digital and networked by default? Women's organisations and the social imaginary of networked feminism» en New Media \& Society, Vol. 18, №6, pp. 1-17.

FRASER, Nancy (2013). Fortunes of Feminism: From State-Managed Capitalism to Neoliberal Crisis, Londres: Verso Books.

FUCHS, Christian (2014). Social Media: a critical introduction, London: Sage.

FUCHS, Christian y Sebastian SEVIGNANI (2013). «What is Digital Labour? What is Digital Work? What's their Difference? And why do these Questions Matter for Understanding Social Media?» en TripleC, N¹1, pp. 237-293.

FUEYO, Aquilina y María FERNÁNDEZ (2018). «¿Empoderadas o violentas? internet, participación sociopolítica y educación en redes sociales desde un enfoque feminista» en APARICI, Roberto; ESCAÑO, Carlos y David García (eds.) (2018). La otra educación: pedagogías críticas para el siglo XXI, España: UNED, Universidad Nacional de Educación a Distancia, pp. 243-256.

GIDDENS, Anthony (1994). Modernidad e identidad del yo. El yo y la sociedad en la época contemporánea, Barcelona: Península. 
GUIL, Ana (2011). «Redes sociales y praxis ciberfeminista: Nuevas alianzas en Internet» en Asparkía, № 22, pp. 73-83.

haraWAY, Donna (2016). Manifiesto para Cyborgs. Ciencia, tecnología y feminismo socialista a finales del siglo XX, Mar de Plata: Puente aéreo.

KEMBER, Sarah (2003). Cyberfeminism and Artificial Life, London: Routledge.

LOZA, Susana (2014). "Hashtag Feminism, \#SolidaritylsForWhiteWomen, and the Other \#FemFuture», en Ada: A Journal of Gender, New Media, and Technology, №5. Disponible en: https://adanewmedia.org/2014/07/issue5-loza/. (Fecha de consulta: 19/12/2018).

MALDONADO, Tere y Anabel SANZ (2004). «Movimiento feminista. Feminismo siglo XXI notas para un balance y perspectivas» en IBARRA, Pedro y Elena GRAU (eds.) (2004). Anuario de movimientos sociales [2003]: la red en la calle: ¿̇cambios en la cultura de movilización?, Barcelona: Icaria, pp.108-119.

MARWICK, Alice (2010). Status Update: Celebrity, Publicity and Self-Branding in Web 2.0, Nueva York: New York University.

MILAN, Stefania y Miren GUTIÉRREZ (2015). «Medios ciudadanos y big data: La emergencia del activismo de datos» en Mediaciones, $\mathrm{N}^{\circ} 14$, pp. 10-26.

MONTERO, Justa (2005). «Movimiento feminista iniciativas y debates en el feminismo», en lBARRA, Pedro y Elena Grau (eds.) (2005). La red en la encrucijada: anuario de movimientos sociales, Barcelona: Icaria, pp. 130-134.

NÚÑEZ, Sonia (2011). «Activismo y colectivos en red: praxis feminista "online" y violencia de género» en Asparkía, №22, pp. 85-98.

NÚÑEZ, Sonia et al. (2012). «Una práctica política efectiva de agencia femenina en la Red: praxis feminista on line contra la violencia de género en España» en Telos: Cuadernos de Comunicación e Innovación, N92, pp. 60-69.

ROVIRA, Guiomar (2017). Activismo en red y multitudes conectadas, Barcelona: Icaria.

SANZ, Verónica (2006). «Las tecnologías de la información desde el punto de vista del género: posturas y propuestas desde el feminismo» en Isegoría, №34, pp. 193-208.

SIEMENS, George (2004). «Connectivism: A Learning Theory for the Digital Age» en International Journal of Instructional Technology and Distance Learning, №2, pp. 3-10.

TRERÉ, Emiliano (2016). «Distorsiones tecno políticas: represión y resistencia algorítmica del activismo ciudadano en la era del big data» en Trípodos, №39, pp. 35-51.

(2013). «\#仿oy 123: la experiencias de los nuevos movimientos sociales en México y el papel de las redes sociales desde una perspectiva crítica" en Revista de Intervención Socioeducativa, $N^{\circ} 55$, pp. 112-121.

166

Dossiers Feministes, 25, 2019, 147-167 - ISSN: $1139-1219$ - e-ISSN: 2340-4930 - DOI: http://dx.doi.org/10.6035/Dossiers.2019.25.10 
TRERÉ, Emiliano y Alejandro BARRANQUERO (2013). «De mitos y sublimes digitales: movimientos sociales y tecnologías de la comunicación desde una perspectiva histórica» en Revista de Estudios para el Desarrollo Social de la Comunicación, Nº, pp. 27-47.

VAN DIJCK, José (2016). La cultura de la conectividad. Una historia crítica de las redes sociales, Buenos Aires: Siglo Veintiuno.

WAJCMAN, Judy (2006). El tecnofeminismo, Madrid: Cátedra.

ZAFRA, Remedios (2011). «Un cuarto propio conectado. Feminismo y creación desde la esfera público-privada online» en Asparkía, №22, pp. 115- 129.

(2005). Netianas. N(h)acer mujer en Internet, Madrid: Lengua de Trapo. 